\title{
EVIDÊNCIA E SIGNIFICAÇÃO NAS INVESTIGAÇÕES LÓGICAS: O PAPEL DO CONCEITO DE EVIDêNCIA NA SEMÂNTICA E NA EPISTEMOLOGIA DE HUSSERL
}

\author{
Evidence and Meaning in Logical Investigations: the role of evidence in Husserl's semantics and
}

epistemology

Resumo: Este artigo visa analisar as relações entre a teoria semântica, psicológica e epistemológica das Investigações Lógicas (1900-1901). Iremos mostrar que, dentre os vários problemas conceituais e terminológicos presentes no texto de Edmund Husserl (1859-1938), consideramos significativo o problema que pode ser enunciado na seguinte questão: como ato psíquico, significação ideal e objeto real conseguem estabelecer uma relação de correspondência? Como atestar tal correspondência? Husserl responde a essa questão clarificando o conhecimento enquanto uma síntese constante de preenchimentos de significação, isto é, como síntese progressiva de correspondência e satisfação entre expressão, significação e objeto, que, por fim, culmina no ideal limite do conhecimento: a evidência, que é o ato psíquico que reconhece e afirma a correspondência completa e a mais total possível. Baseando-nos em vários comentadores concentrados nos problemas semânticos, linguísticos e epistemológicos presentes nas Investigações Lógicas, mostraremos que se: a) dissolvermos alguns equívocos terminológicos e conceituais, b) clarificarmos o papel do conceito de evidência tanto como critério semântico quanto epistemológico de verdade, dentro do contexto das I, V e VI Investigações Lógicas, e, por conseguinte, c) elucidarmos a diferença entre o caráter posicional e caráter ontológico na dinâmica da evidência; então é possível sustentar uma semântica ideal, apreensível e objetiva

Palavras-chave: Conhecimento. Evidência. Significação.

\begin{abstract}
This article aims to analyze the relations between the semantic, psychologic and the epistemological theories of Logical Investigations (1900-1901). We will show that in various conceptual and terminological problems present in Husserl's text, we consider meaningful the problem which may be enunciated in the question as follows: how a psychic act, ideal meaning and real object achieves to establish a correspondence relation? How attest such correspondence? Husserl answers by clarifying the knowledge as a progressive synthesis of correspondence and satisfaction between expression, meaning and object that, ultimately, culminates at the ideal limit of knowledge: the evidence, which is the psychic act that recognizes and affirms the complete and more total possible correspondence. Basing us in various commentators focused on semantic, linguistic and epistemological problems presented in the Logical Investigations, we will show that if: a) we dissolve some terminological and conceptual misunderstandings, b) to clarify the role of the concept of evidence as much a semantic as epistemological criterion of truth, in the context of I, $\mathrm{V}$ and VI Investigations, and, consequently, c) if we elucidate the difference between the positional and ontological character in the dynamics of evidence; then it's possible to bear a ideal, apprehensible and objective semantics
\end{abstract}

Keywords: Knowledge. Evidence. Meaning.

* Mestrando em Filosofia pela UEL-PR. Bolsista Capes. Contato: joseph.requiem@gmail.com

\begin{tabular}{|c|c|c|c|c|c|}
\hline intuitio & $\begin{array}{c}\text { ISSN } \\
1983-4012\end{array}$ & Porto Alegre & Vol.9- No.1 & $\begin{array}{c}\text { Julho } \\
2016\end{array}$ & p.35-52 \\
\hline
\end{tabular}




\section{Introdução}

Nosso trabalho se situa no contexto da obra Investigações Lógicas (1990-1901) de Edmund Husserl (1859-1938), e tem como temática as análises da linguagem, da psicologia descritiva e das significações, que se relacionam em uma clarificação fenomenológica de natureza epistemológica. Especificamente, este estudo analisa e procura elucidar as seguintes questões, visando uma hipótese adequada para respondê-las: como dar garantia de que um ato psíquico "vazio" e simbólico, a saber, a expressão, e o objeto a que remete podem entrar em correspondência? O que faz "tornar claro" tal correspondência? Os problemas se tornam mais intrincados quando questionamos uma das teses mais significativas das Investigações Lógicas: as significações das expressões, enquanto objetos ideais (nãoempíricos) podem ser apreensíveis, e tal apreensão pode ser atestada objetivamente, isto é, com evidência. De fato, nosso objetivo é fornecer uma hipótese que mostre soluções para tais problemas: que o conceito de evidência, nesta obra, se interpretado como um critério de verdade, tanto semântico como epistemológico, pode ser um caminho para a solução destes problemas.

Para mostrar tanto a coerência e consistência desta hipótese com o texto de Husserl quanto às respostas aos problemas supracitados, iremos dirigir nosso estudo por três caminhos:

a) Clarificação dos conceitos das $I, V$ e VI Investigações Lógicas, principalmente os equívocos terminológicos e conceituais mais comuns;

b) Clarificação do conceito de evidência neste texto, mostrando a pertinência de nossa interpretação, e, por fim,

c) Elucidaremos como o caráter posicional do ato de evidência não implica um comprometimento metafísico, mas epistemológico.

Nosso estudo será iniciado por uma reconstrução das descrições e argumentações das $I, V$ e $V I$ Investigações; após isso, confrontaremos e explicitaremos alguns equívocos fundamentais com relação ao conceito de evidência nas Investigações; por fim, iremos clarificar como é possível sustentar a nossa hipótese e como ela resolve os principais problemas a que se remete este estudo.

Os méritos deste estudo, com efeito, se concentram em dois aspectos, a saber, de elucidar e fazer uma análise tanto terminológica quanto conceitual do conceito de evidência que comprove a pertinência de nossa hipótese, quanto propor uma solução diferenciada destes problemas que citamos, reavaliando as respostas dadas pelo próprio Husserl.

A hipótese será, portanto, de grande valia como interpretação possível destes problemas nesta fase da filosofia de Edmund Husserl, no que concerne a uma interpretação para o conceito de evidência quanto

\begin{tabular}{|c|c|c|c|c|c|}
\hline intuitio & $\begin{array}{c}\text { ISSN } \\
1983-4012 \\
\end{array}$ & Porto Alegre & Vol. $9-\mathrm{N}^{\mathrm{o}} .1$ & $\begin{array}{l}\text { Julho } \\
2016 \\
\end{array}$ & p.35-52 \\
\hline
\end{tabular}


Evidência e Significação nas Investigações Lógicas: o papel do conceito de evidência na semântica e na epistemologia de Husserl

para uma análise dos problemas epistemológicos e semânticos do "realismo lógico" husserliano da obra de 1900-1901. Não queremos, entretanto, propor como única a nossa interpretação e nossa estratégia de solução de tais problemas, mas apenas propor uma clarificação, coerente ao texto do autor e teoricamente consistente, como já dissemos, de alguns dos mais importantes problemas que tal obra suscita.

\section{A I Investigação e o problema da linguagem}

As Investigações Lógicas, mesmo sem constituírem um todo linear, no tocante às matérias e problemas, mantém uma estrutura argumentativa sistemática ${ }^{1}$, cujo início delimita que o interesse de Husserl é não conceber a consciência sob a perspectiva empirista ou psicofisiológica, mas sim efetuar uma “análise gramatical" não empírica das expressões e significações ${ }^{2}$. Com efeito, a I Investigação Lógica, de título Expressão e Significação, é uma descrição e análise das expressões linguísticas quanto ao seu significado e referência objetal. Neste sentido, ato psíquico, objeto, signo e significado lógico compõem um panorama descritivo dirigido por uma intenção de se afastar pressupostos tanto empíricos quanto metafísicos ${ }^{3}$ e proceder a uma investigação que compreenda de maneira pura, direta e formal as relações entre estas instâncias. O claro objetivo é fornecer um fundamento seguro para a Lógica Pura, enquanto sistema objetivo de significados puros e constructo teórico formal em que se fundamenta a lógica, a matemática e as ciências empíricas.

O início da I Investigação faz uma distinção entre signos indicativos e signos significativos ou que são regidos por atos de compreensão. "Um signo "indicativo" é aquele sinal material ou situação objetiva que nos dá como existente outra situação objetiva, ou, em outras palavras, um objeto que serve para

\footnotetext{
${ }^{1}$ Há, na verdade, como Husserl atesta na introdução da segunda edição de 1913, um desenvolvimento crescente e sistemático de dificuldades e análises descritivas, em que as investigações posteriores supõem temas das Investigações anteriores, mesmo sem haver uma intenção unitária em sentido literário (Cf. HUSSERL, E. Investigaciones Lógicas - I Tomo. Traducción del alemán por Manuel García Morente y José Gaos. $2^{\mathrm{a}}$ Ed. Madrid: Revista de Occidente,1967 (Selecta), p. 26, prefácio à Segunda Edição de 1913).

${ }^{2}$ Cf. HUSSERL, E. Investigaciones Lógicas -I Tomo. Traducción del alemán por Maunel García Morente e José

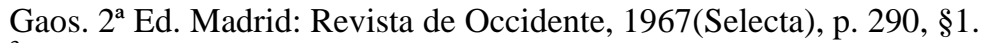

${ }^{3}$ A ideia de redução (neste caso, uma redução eidética, voltada ao essencial os atos psíquicos), aqui apenas implicitamente presente, encontra sua primeira prática exercitada já nas Investigações, segundo o próprio Husserl, embora o projeto de uma redução fenomenológico-transcendental ainda não entrasse em cena. Fenomenologia, no sentido das Investigações Lógicas, é entendida como psicologia eidética descritiva, isto é, a elaboração de análises e descrições que se referem a atos psíquicos e seus objetos, em caráter universal e formal, e não relacionados a uma psicologia empírica. Não há, ainda, o sentido de fenomenologia como estudo formal dos modos de constituição do mundo por meio de uma consciência transcendental. Ver, por exemplo, HUSSERL, E. Investigaciones Lógicas -I Tomo. Traducción del alemán por Maunel García Morente e José Gaos. 2a Ed. Madrid: Revista de Occidente, 1967 (Selecta), p. 499, §37, em que se diferencia a psicologia eidética das Investigações frente com outras acepções de cunho empirista.

${ }^{4}$ Cf. HUSSERL, E. Investigacioens Lógicas - I Tomo.Traducción de Manuel García Morente y José Gaos. $2^{\mathrm{a}}$ Ed. Madrid: Revista de Occidente, 1967(Selecta), p. 315, §1.
}

\begin{tabular}{|c|c|l|l|l|l|}
\hline intuitio & $\begin{array}{c}\text { ISSN } \\
1983-4012\end{array}$ & Porto Alegre & Vol.9- $\mathrm{N}^{\mathrm{o}} .1$ & $\begin{array}{l}\text { Julho } \\
2016\end{array}$ & p.35-52 \\
\hline
\end{tabular}


indicar a existência empírica de outro objeto. Vejamos algunsexemplos de sinais ou signos indicativos: um fóssil que indica a existência de certo animal pré-histórico, ou, ainda, a cor amarela de um indivíduo indicando-lhe a existência de uma icterícia ${ }^{5}$.Vemos que as indicações são casos de comunicação por meio de associações empíricas, sem "sentido" para sujeitos quaisquer.

O signo significativo ou expressão possui também uma natureza indicadora, assim, indica significado ou sentido cognoscível para um ouvinte ou leitor. O caráter específico está justamente no aspecto semântico ${ }^{6}$, ou seja, remeter a um objeto (inclusive algumas vivências próprias) por meio de um sentido. Vemos que a indicação, neste caso, depende fundamentalmente do fato de se intencionar a comunicação de significado ${ }^{7}$. Essa diferença resulta na apreciação especial de Husserl com relação ao caráter introspectivo da "fala interna", em que o sujeito falante pode se utilizar de vivências expressivas sem ver nelas um intuito comunicativo, já que ele possui acesso imediato a estas significações e o objeto a que se referem: as suas próprias vivências ${ }^{8}$.

Husserl, continuando sua análise, descreve em quais atos psíquicos o sujeito interlocutor, por meio do signo material, intenciona significados e como pode satisfazer esta intenção. O primeiro ato psíquico se refere ao conceito de intenção de significação, que descreve como se dá a relação entre o signo material e os atos cognitivos que lhe dão sentido, em uma instância totalmente vazia ou meramente intencional para o falante, sem um objeto a ser apresentado que possa ser significado com a expressão, e que caracteriza, em sentido próprio, as expressões. O preenchimento de tais intenções vazias é como que o preenchimento da expressão, e constitui a outra face correlata do ato simbólico, que é chamada por Husserl de preenchimento de significação ${ }^{9}$. A presença plena do objeto à intenção de significação, fornecida apenas por atos intuitivos (uma percepção ou ato imaginativo), corrobora para que a expressão tenha seu caráter cognitivo satisfeito ${ }^{10}$.

\footnotetext{
${ }^{5}$ Cf. HUSSERL, E. Investigaciones Lógicas - I Tomo. Traducción del alemán por Manuel García Morente y José Gaos. $2^{\text {a }}$ Ed. Madrid: Revista de Occidente, 1967(Selecta), p. 316, §2 e p. 322, §4)

${ }^{6}$ Chamamos, portanto, de "semântica" (mesmo que Husserl não use este termo) a análise das expressões e dos significados que Husserl efetua ao longo de suas Investigações Lógicas, acentuando, a todo o momento, o diferencial de ser uma análise fenomenológica, e, de um modo bem específico, psicologia eidética descritiva.

${ }^{7}$ HUSSERL, E. Investigaciones Lógicas - I Tomo. Traducción del alemán por Manuel García Morente y José Gaos. $2^{a}$ Ed. Madrid: Revista de Occidente, 1967(Selecta), p. 324-326, §6 e 7.

${ }^{8} \mathrm{cf}$. KUSCH, M. Linguagem como Cálculo versus Linguagem como Meio Universal: um estudo sobre Husserl, Heidegger e Gadamer. Tradução de Dankwart Bernsmüller. 1 ${ }^{a}$ Ed. São Leopoldo: Editora UNISINOS, 2001, p. 72, e HUSSERL, E. Investigaciones Lógicas - I Tomo. Traducción del alemán por Manuel García Morente y José Gaos. 2a Ed. Madrid: Revista de Occidente, 1967(Selecta) p.327-328, §8.
}

${ }^{9}$ HUSSERL, E.Investigaciones Lógicas - I Tomo. Traducción del alemán por Manuel García Morente y José Gaos. $2^{\text {a }}$ Ed. Madrid: Revista de Occidente, 1967(Selecta), p. 330, §9)

${ }^{10} \mathrm{Cf}$. HUSSERL, E. Investigaciones Lógicas - I Tomo. Traducción del alemán por Manuel García Morente y José

\begin{tabular}{|c|c|l|l|l|l|}
\hline intuitio & $\begin{array}{c}\text { ISSN } \\
1983-4012\end{array}$ & Porto Alegre & Vol.9- No.1 & $\begin{array}{l}\text { Julho } \\
2016\end{array}$ & p.35-52 \\
\hline
\end{tabular}


Husserl tem o cuidado de distinguir o processo de expressar segundo a) o ato psíquico que intenciona significar um objeto b) o ato que preenche a referência objetiva e o significado c) o objeto a ser significado, e d) o conteúdo da intenção (conteúdo vazio e simbólico) e do preenchimento intuitivo (de um objeto real ou ideal) ${ }^{11}$. A esfera do significado tem sua plenitude nos atos intuitivos, e o objeto não pode apenas receber significado para o sujeito que expressa apenas por uma intenção vazia e incompleta. A objetividade do sentido das expressões linguísticas, além de um caráter semântico, tem um caráter epistemológico importante. O objeto é significado como ele aparece nas vivências intuitivas e é representado na intuição ou na percepção, e a intenção incompleta só recebe plenitude pela sua "satisfação" nesta objetividade, como pudemos ver acima. O significado, tanto em sua face meramente intencional como impletiva ${ }^{12}$, tem como satisfação um conteúdo ideal ${ }^{13}$, não submetida às vivências de indivíduos particulares ou objetos empíricos, e por isso, intersubjetiva em razão de sua objetividade formal e sua possibilidade de ter como instâncias vários objetos possíveis. O significado do conceito de "vermelho" tem como possíveis instâncias objetais, por exemplo, um vestido vermelho, uma folha de papel vermelha, uma lâmpada vermelha, etc. Assim está, portanto, assegurado tanto à significação das expressões acerca dos objetos sensíveis quanto o do significado das proposições da matemática e da lógica.

Husserl analisa como sentidos das expressões e as significações puras se relacionam com objetos a que se referem e, neste sentido, classifica as diferenças entre os vários tipos de expressões. O primeiro campo a se determinar é o dos nomes. Existem nomes equívocos (com vários sentidos), multívocos (vários sentidos e objetos), conceitos ou nomes plurivalentes (como os que designam classes, em que é possível a satisfação impletiva de vários objetos) e, por fim, unívocos, ou seja, de significação única e determinada, ao passo que podem existir expressões que não tem significação determinada, ou são apenas determinadas pela percepção sensível. São as expressões essencialmente ocasionais, cujo objeto e significação são determinados pela circunstância empírica imediata, mas ainda aqui não se perde o caráter ideal do significado de tais expressões. As expressões compostas que tem a significação determinada, assim como seu objeto, diferentes das ocasionais, que são chamadas de "subjetivas", são, por sua vez, "objetivas ${ }^{14 "}$.

Gaos. 2a Ed. Madrid: Revista de Occidente, 1967(Selecta), p. 333, §10).

${ }^{11}$ HUSSERL, E. Investigaciones Lógicas - I Tomo. Traducción del alemán por Manuel García Morente y José Gaos. 2a Ed. Madrid: Revista de Occidente (Selecta), 1967, p. 338, §12.

${ }^{12}$ Husserl utiliza este vocábulo derivado da palavra latina implere (que significa "deixar pleno, preencher”) para designar os atos de preenchimentos de significação e os significados obtidos nestes atos.

${ }^{13}$ Cf. HUSSERL, Edmund. Investigaciones Lógicas - I Tomo. Traducción del alemán por Manuel García Morente y José Gaos. $2^{\text {a }}$ Ed. Madrid: Revista de Occidente (Selecta), 1967, p. 335, §11 e §31.

${ }^{14}$ Cf. HUSSERL, Edmund. Investigaciones Lógicas - I Tomo. Traducción del alemán por Manuel García Morente y José Gaos. $2^{a}$ Ed. Madrid: Revista de Occidente (Selecta), 1967(I), p. 373 e 374, §26.

\begin{tabular}{|c|c|l|l|l|l|}
\hline intuitio & $\begin{array}{c}\text { ISSN } \\
1983-4012\end{array}$ & Porto Alegre & Vol.9- $\mathrm{N}^{\mathrm{o}} .1$ & $\begin{array}{l}\text { Julho } \\
2016\end{array}$ & p.35-52 \\
\hline
\end{tabular}


Evidência e Significação nas Investigações Lógicas: o papel do conceito de evidência na semântica e na epistemologia de Husserl

Contudo, a tese da unidade ideal da significação ainda é mantida, pois a percepção apenas determina a apreensão da significação e não constitui per se a espécie ideal.

\section{A V e a VI Investigação: elucidações psicológicas e epistemológicas da linguagem}

Na continuidade do texto de Husserl, vemos que os problemas deixados pela I Investigação, como a possibilidade de se captar uma significação pura por atos psíquicos e, especificamente, atos expressivos, exigem uma elucidação psicológica e epistemológica mais acurada. A V Investigação (Sobre as Vivências Intencionais e seus Conteúdos) e a VI Investigação (Elementos de uma Elucidação Fenomenológica do Conhecimento) têm como meta a clarificação destas noções e a descrição de como se dá os processos cognitivos próprios a cada ato psíquico que entra em cena no conhecimento lógico. Ainda, como se dá o acesso verdadeiro e evidente às significações e aos objetos.

De início, na V Investigação, o conceito de consciência em Husserl está intrinsecamente unido ao conceito de intencionalidade. Consciência, em um sentido ideal e próprio, é vivência intencional, isto é, é ter uma vida psíquica cuja meta é sempre uma referência objetiva, seja de qual maneira for. Nas percepções, percebemos algo; no juízo, ajuizamos sobre algo; no desejo, desejamos algo, e assim em qualquer vivência consciente ${ }^{15}$.

Para Husserl, devem-se elucidar dois aspectos essenciais dos atos ou vivências intencionais: elas possuem uma essência, um aspecto ideal e específico que pode ser estruturado na descrição fenomenológica. Tal essência pode ser intencional ou significativa. A primeira estrutura ideal designa as propriedades do ato psíquico referentes à própria referência objetiva e de como é vivida tal referência. A este aspecto dá-se o nome de qualidade intencional e àquele, o nome de matéria intencional. No que tange à essência significativa, dá-se a descrição da vivência enquanto atuante nos atos de expressão, nas intenções de significação ${ }^{16}$.

Husserl também descreve idealmente não só como se dá a estrutura dos atos, mas as relações entre as diversas vivências. Neste caso, descrevem-se as vivências nas suas relações de fundação e dependência. Há vivências fundantes ou independentes, que não são parte de uma ou várias vivências, e vivências fundadas e dependentes, que são como que partes de um todo de atos ou são vividos como que sob a base

${ }^{15}$ (cf. HUSSERL, E. Investigaciones Lógicas - II Tomo. Traducción del alemán por Manuel García Morente y José Gaos. 2 ${ }^{a}$ Ed. Madrid: Revista de Occidente, 1967 (Selecta), p. 170, §10)

${ }^{16}$ (cf. HUSSERL, E. Investigaciones Lógicas - II Tomo. Traducción del alemán por Manuel García Morente y José Gaos. $2^{\text {a }}$ Ed. Madrid: Revista de Occidente, 1967(Selecta, pp.214-219, §20 e pp.219-224, §21)

\begin{tabular}{|c|c|c|c|c|c|}
\hline intuitio & $\begin{array}{c}\text { ISSN } \\
1983-4012 \\
\end{array}$ & Porto Alegre & Vol. $9-\mathrm{N}^{\mathrm{o}} .1$ & $\begin{array}{l}\text { Julho } \\
2016 \\
\end{array}$ & p.35-52 \\
\hline
\end{tabular}


Evidência e Significação nas Investigações Lógicas: o papel do conceito de evidência na semântica e na epistemologia de Husserl

dos atos fundantes ${ }^{17}$. Um juízo é uma vivência fundada, pois supõe como partes fundantes a vivência do objeto julgado e a vivência do julgar (afirmar ou negar uma propriedade ao objeto).

Podemos descrever como vivências fundantes os atos nominais e os atos objetivantes, ou as representações nominais e objetivantes. No caso das representações ou atos nominais, há uma vivência do objeto intencional de um modo expressivo, ou seja, em sua função dento de uma proposição. $\mathrm{O}$ ato ou representação objetivante, por sua vez, é uma vivência imediata do próprio objeto intencional, em que este fica determinado "em si”, sem intermediários simbólicos e sem associação a outros objetos ${ }^{18}$. Em suma, a classe dos atos objetivantes inclui também a dos nominais, diferenciando-se, de fato, o caráter simbólico ou intuitivo dos mesmos. Os atos objetivantes, segundo Husserl, podem ser divididos em nominais (que são posicionais ou não-posicionais, ou seja, afirma ou nega a existência de objetos) e proposicionais (que são téticos ou não téticos, ou seja, afirmam ou negam propriedades de estados de coisas - são base para os juízos $)^{19}$.

O caráter qualitativo de representação é importante, e deve ser dilucidado melhor, pois a matéria intencional sempre tem como base uma representação objetivante, ou ainda, é ela mesma uma representação objetivante, tomando posição sobre os objetos a que se referem. Representação, com efeito, designa qualquer ato independente que apresenta à vivência um objeto, ou simbolicamente, ou de modo direto e próprio. Portanto, um ato que nos dê algo como "objetivo", mesmo sem tomar posição acerca de sua existência, qualifica-se como uma representação ${ }^{20}$. Portanto, constituem-se como fundantes na clarificação do conhecimento lógico, pois em enunciados, temos como base representações ou atos objetivantes direcionados aos objetos a que se refere o enunciado.

A argumentação e descrições de Husserl continuam na problemática de se definir, sobre a base de sua psicologia descritiva, as relações entre representações simbólicas e intuitivas, e como o conhecimento simbólico fundamenta ou suporta um conhecimento de graduação elevada, como o intuitivo (perceptivo ou afigurativo/imaginativo). Os temas de intenção e preenchimento são reconsiderados em sua relação com a vivência em sua essência intencional. Significação, percepção sensível e intuição desempenham um

${ }^{17}$ (cf. HUSSERL, E. Investigaciones Lógicas - II Tomo. Traducción del alemán por Manuel García Morente y José Gaos. $2^{\text {a }}$ Ed. Madrid: Revista de Occidente,1967(Selecta), p. 206-208, §18)

${ }^{18}$ (cf. HUSSERL, E. Investigaciones Lógicas - II Tomo. Traducción de Manuel García Morente y José Gaos. $2^{\mathrm{a}}$ Ed. Madrid: Revista de Occidente,1967(Selecta), p.283, §37 e p. 284, §38.

${ }^{19}$ Ver MALDONADO, C. E. Introducción a la Fenomenología a partir de la Idea de Mundo: la filosofia de Husserl. $1^{a}$ Ed. Santafé de Bogotá: (CEJA), p. 52, e HUSSERL, Edmund. Investigaciones Lógicas - II Tomo. Traducción de Manuel García Morente y José Gaos. Madrid: Revista de Occidente, 1967(Selecta), p.262-266, §33e HUSSERL, Edmund. Investigaciones Lógicas - II Tomo. Traducción de Manuel García Morente y José Gaos. Madrid: Revista de Occidente,1967 (Selecta), p.266-269, §34.

${ }^{20}$ (HUSSERL, E. Investigaciones Lógicas - II Tomo. Traducción de Manuel García Morente y José Gaos. $2^{\mathrm{a}}$ Ed. Madrid: Revista de Occidente, 1967(Selecta), p. 263, §33).

\begin{tabular}{|c|c|c|c|c|c|}
\hline intuitio & $\begin{array}{c}\text { ISSN } \\
1983-4012\end{array}$ & Porto Alegre & Vol.9- $\mathrm{N}^{\circ} .1$ & $\begin{array}{l}\text { Julho } \\
2016\end{array}$ & p.35-52 \\
\hline
\end{tabular}


Evidência e Significação nas Investigações Lógicas: o papel do conceito de evidência na semântica e na epistemologia de Husserl

papel cognitivo de grande importância para o problema da possibilidade de um conhecimento, tanto de natureza lógica como problema epistemológico.

Como é sabido, o princípio fenomenológico de que, epistemologicamente, a intuição tem preponderância sobre o conhecimento simbólico e representacional (no sentido de Husserl) é de importância capital no segundo capítulo da VI Investigação Lógicas. Os atos objetivantes são os próprios atos do conhecimento em sentido estrito, enquanto que os atos significantes serão aqui descritos como um conjunto contido nestes anteriores; mas, afinal no que consiste neste contexto o ato significante ${ }^{21}$, se todos os atos são fundados em atos objetivantes? A classe dos atos objetivantes também abarca a classe das expressões? Parece que a conclusão de Husserl se inclina a conceber a unidade de ato que caracteriza a expressão (intenção e preenchimento de significação - pensamento e intuição) como fundada sobre atos objetivantes, que também engloba, como atos que são objetos de atos posteriores, a percepção e a imaginação ${ }^{22}$.

Qual é a relação entre estas duas classes de atos, já que ato signitivo e ato objetivante são de uma mesma classe, mas de matérias diversas? Necessita-se, então, descrever como os conteúdos representacionais entram em relação na dinâmica do conhecimento. Primeiramente, conteúdo representacional pode ser conteúdo intuitivo, que é a própria consciência imediata de classificação do objeto já doado. Já o conteúdo signitivo é uma característica de conteúdo representacional que não apresenta e nem tem o objeto intencional doado, mas significado ou "meramente pensado", portanto, conhecimento mediato ${ }^{23}$.

De caráter posicionante, os sucessivos preenchimentos e sínteses destes atos e seus conteúdos (simbólicos, presentativos ou analogizantes) se dão em atos de identificação e classificação. Este desenrolar de identificações e classificações tem como limite ideal a evidência, onde todas as representações simbólicas e teores simbólicos são satisfeitos por atos objetivantes. Evidência, para Husserl, designa o caráter próprio e critério epistemológico fundamental para distinguir os atos de preenchimento e de identificação. A adequação é o ideal limite em que a evidência desempenha papel

\footnotetext{
${ }^{21}$ Ato significante é o termo que Husserl usa para designar qualquer ato que capta objetos por meio de signos, como as expressões. É o mesmo, conceitualmente falando, que ato expressivo.

${ }^{22} \mathrm{Cf}$. HUSSERL, E. Investigações Lógicas - VI Investigação Lógica (Elementos de uma Elucidação Fenomenológica do Conhecimento). Tradução de Zeljko Loparic e Andreia Maria Altino de Campos Loparic. $2^{\circ}$ Ed. São Paulo: Abril Cultural, 1979 ( $2^{\circ}$ Ed.), p. 43, §13, final.

${ }^{23}$ HUSSERL, E. Investigações Lógicas - VI Investigação Lógica (Elementos de uma Elucidação Fenomenológica do Conhecimento). Tradução de Zeljko Loparic e Andreia Maria Altino de Campos Loparic. $2^{\circ}$ Ed. São Paulo: Abril Cultural, 1979 ( $2^{\circ}$ Ed.), p. 74, §27, c.
}

\begin{tabular}{|c|c|c|c|c|c|}
\hline intuitio & $\begin{array}{c}\text { ISSN } \\
1983-4012\end{array}$ & Porto Alegre & Vol.9- $\mathrm{N}^{\circ} .1$ & $\begin{array}{l}\text { Julho } \\
2016\end{array}$ & p.35-52 \\
\hline
\end{tabular}


Evidência e Significação nas Investigações Lógicas: o papel do conceito de evidência na semântica e na epistemologia de Husserl

importante para que a verdade, ou seja, a síntese identificadora ou ato identificador de uma vivência e seu correlato objetivo. $^{24}$

Entendamos como esse estado de coisas se dá, de maneira mais pormenorizada. Em primeiro lugar, a intenção de significação serve de representação base a um ato posicional de grau superior, ou seja, um juízo que afirme um estado de coisas. A graduação de adequação à intenção fundamentadora se dá por meio de preenchimentos perceptivos sucessivos, é a completa "presentificação" ${ }^{25}$ do objeto e a adequação total e perfeita do objeto à intenção de significação. O sentido estrito de evidência refere-se ao próprio resultado deste processo: é a síntese perfeita e a adequação perfeita entre preenchimento e intenção, o pensamento do objeto (sensível ou ideal) e sua aparição como ele é propriamente. Segundo Husserl, o objeto é efetivamente dado à intenção de significação. Neste sentido, o correlato da evidência é a própria $\operatorname{verdade}^{26}$.

Esta dinâmica inteira deve, conforme as pretensões das Investigações Lógicas, garantir o conhecimento referente aos objetos ideais. Neste sentido, entender como se podem ter conhecimentos de objetos ideais exige que Husserl trabalhe com uma diferenciação na percepção: temos percepções individuais e empíricas, que são sensíveis, e percepções gerais e não empíricas, que são categoriais. As primeiras são fundantes e independentes, isto é, não dependem da cognição de outros objetos e é base para outros objetos. O segundo tipo de percepção é categorial, dependente da fundação em percepções sensíveis (não são captados por generalização indutiva), e que se mostram por atos sintéticos. Tais objetos são os predicados, as cópulas, os termos lógicos vários (e, ou, todo, algum, etc.) e as relações ${ }^{27}$.

Na psicologia descritiva de Husserl, há uma diferença entre percepções categoriais de proposições relacionais simples como "esta caneta está dentro deste estojo nesta mesa" e complexas como "têm-se A

\footnotetext{
${ }^{24}$ HUSSERL, E. Investigações Lógicas - VI Investigação Lógica (Elementos de uma Elucidação Fenomenológica do Conhecimento). Tradução de Zeljko Loparic e Andreia Maria Altino de Campos Loparic. $2^{\circ}$ Ed. São Paulo: Abril Cultural, 1979 ( $2^{\circ}$ Ed.), p. 93-94, $\$ 38$.

${ }^{25}$ Do alemão vergegenwärtigung, e é a característica posicional principal dos conteúdos e atos perceptivos: "tornar presente" o próprio objeto como foi intencionado. Ver glossário feito pelos tradutores em HUSSERL, E. Investigações Lógicas - VI Investigação Lógica (Elementos de uma Elucidação Fenomenológica do Conhecimento). Tradução de Zeljko Loparic e Andreia Maria Altino de Campos Loparic. $2^{\circ}$ Ed. São Paulo: Abril Cultural, 1979, p. 183 e nota de rodapé 80 em HUSSERL, E. Investigações Lógicas - VI Investigação Lógica (Elementos de uma Elucidação Fenomenológica do Conhecimento). Tradução de Zeljko Loparic e Andreia Maria Altino de Campos Loparic. $2^{\circ}$ Ed. São Paulo: Abril Cultural, 1979, p.59.

${ }^{26} \mathrm{Cf}$. HUSSERL, E. Investigações Lógicas - VI Investigação Lógica (Elementos de uma Elucidação Fenomenológica do Conhecimento). Tradução de Zeljko Loparic e Andreia Maria Altino de Campos Loparic. $2^{\circ}$ Ed. São Paulo: Abril Cultural, 1979, p. 94, §39.

${ }^{27}$ HUSSERL, E. Investigações Lógicas - VI Investigação Lógica (Elementos de uma Elucidação Fenomenológica do Conhecimento). Tradução de Zeljko Loparic e Andreia Maria Altino de Campos Loparic. $2^{\circ}$ Ed. São Paulo: Abril Cultural, 1979, p.118, §48 e cf. KUSCH, M. Linguagem como Cálculo versus Linguagem como Meio Universal: um estudo sobre Husserl, Heidegger e Gadamer. Tradução de Dankwart Bernsmüller. $1^{a}$ Ed. São Leopoldo: Editora UNISINOS, 2001, p. 90 e 91.
}

\begin{tabular}{|c|c|c|c|c|c|}
\hline intuitio & $\begin{array}{c}\text { ISSN } \\
1983-4012\end{array}$ & Porto Alegre & Vol.9- $\mathrm{N}^{\circ} .1$ & $\begin{array}{l}\text { Julho } \\
2016\end{array}$ & p.35-52 \\
\hline
\end{tabular}


Evidência e Significação nas Investigações Lógicas: o papel do conceito de evidência na semântica e na epistemologia de Husserl

ou B; tenho não-B; logo, se tem A”. A diferença reside nos possíveis preenchimentos perceptivos das intenções sobre os objetos ou estados de coisas categoriais, ou ainda, possíveis fundações em objetos sensíveis $^{28}$. No caso da regra lógica que usamos como exemplo (silogismo disjuntivo), há a possibilidade de se poder variar as instancias de percepções sensíveis que fundam tal enunciado. É, pois um enunciado analítico. No caso anterior de asserção estritamente empírica, se eu variar os objetos para "caneta", “mesa" e "estojo", já não há mais preenchimento possível, e nem evidência.

\section{Alguns problemas na relação entre semântica e epistemologia nas Investigações Lógicas}

A relação entre semântica e epistemologia, segundo o itinerário textual e teórico das Investigações, é progressiva, isto é, Husserl parte de conceitos de expressão e intenção de significação (pertencentes à semântica) para se chegar aos conceitos de adequação e verdade ${ }^{29}$ (pertencentes ao âmbito epistemológico), pois sempre se parte de uma instância vazia e meramente simbólica para outra instância de apreensão plena dos objetos. Desde as relações entre intenção e preenchimento de significação, até as sínteses de preenchimento em relação dinâmica rumo à evidência e verdade, estas duas instâncias de investigação permanecem sempre abertas a descrições cada vez mais pormenorizadas sobre as possibilidades de, por meio de símbolos, apreender objetos, e como unidades lógicas ideais entram na vida psíquica e linguística, sem perda de objetividade. De um modo geral, imediato e mediato, subjetivo e objetivo, simbólico e intuitivo, são analisados com vistas a determinar como é possível uma síntese entre duas instâncias que não podem se confundir.

Contudo, há inúmeros problemas, que se mesclam tanto com as descrições psicológicas quanto aos conceitos epistemológicos e semânticos principais. O que será abordado em nosso trabalho é o seguinte: adotar uma concepção da natureza dos objetos ideais como unidades semânticas não empíricas realmente livra Husserl de um platonismo semântico? ${ }^{30}$ Husserl admite um terceiro reino de entidades, isto é, existiriam, na realidade, objetos empíricos, atos psíquicos e significações? Por outro lado, se o correlato

\footnotetext{
${ }^{28}$ HUSSERL, E. Investigações Lógicas - VI Investigação Lógica (Elementos de uma Elucidação Fenomenológica do Conhecimento). Tradução de Zeljko Loparic e Andreia Maria Altino de Campos Loparic. $2^{\circ}$ Ed. São Paulo: Abril Cultural, 1979, p. 138, §60.

${ }^{29}$ No caso, verdade se refere à apreensão evidente e plena de um objeto. Adiante, em nosso trabalho, elucidaremos o conceito de evidência enquanto um critério de verdade submetido a uma acepção semântica. Assim, o conceito de verdade está relacionado tanto ao âmbito semântico quanto ao âmbito epistemológico. A relação entre estas duas acepções será estudada na seção seguinte.

${ }^{30}$ Husserl se considera distinto do platonismo, justamente por considerar a objetividade das significações como diferente de uma existência metafísica ("em si mesma" desses objetos, em outro mundo fora das vivências psíquicas e das expressões) e uma existência meramente psicológica (criações psicológicas ou meras representações); ele chama esta perspectiva de "exagero do realismo platonizante" (HUSSERL, E. Investigaciones Lógicas - I Tomo. Traducción del alemán por Manuel García Morente y José Gaos. 2a Ed. Madrid: Revista de Occidente, 1967 (Selecta), p. 417-418, §8).
}

\begin{tabular}{|c|c|l|l|l|l|}
\hline intuitio & $\begin{array}{c}\text { ISSN } \\
1983-4012\end{array}$ & Porto Alegre & Vol.9- $\mathrm{N}^{\mathrm{o}} .1$ & $\begin{array}{l}\text { Julho } \\
2016\end{array}$ & p.35-52 \\
\hline
\end{tabular}


Evidência e Significação nas Investigações Lógicas: o papel do conceito de evidência na semântica e na epistemologia de Husserl

da evidência é a verdade, e a última é o estado de coisas evidente, então o ato de evidência servirá de síntese entre o simbólico-psicológico e epistemológico das Investigações, e síntese compreensiva, adequada e que dá à consciência a identidade entre objeto expressado e objeto intuído. Todavia, a evidência é um ato objetivante, e ainda, um ato psíquico (tomado eideticamente). Será que a verdade depende de uma posição subjetiva, e a constatação da adequação ou correspondência é uma constatação também subjetiva, sendo que a verdade exige objetividade absoluta?

Vejamos, com base nas Investigações Lógicas, como resolver estes problemas. A psicologia intencional pode fornecer estrutura conceitual e descritiva que já é direcionada para tais problemas. Ora, a intencionalidade é uma característica subjetiva que visa, em si mesma, instâncias objetivas. Outro aspecto é o descompromisso ontológico que a psicologia eidética husserliana possui com relação à objetividade visada: o objeto intencional, mesmo que ilusório, absurdo, contraditório ou inexistente, ainda é objeto de descrição enquanto correlato de uma vivência intencional, enquanto ele mesmo "fenômeno"31.

O que se depreende disso é que, na análise psicológica e epistemológica husserlianas, os objetos ideais são de grande interesse para entender como a objetividade e validade destes entra no ato psíquico, por meio de abstrações ideatórias e intuições categoriais, tornando necessária a clarificação epistemológica da apreensão deste tipo de objetos, dos quais a lógica pura trata por meio de suas conexões e combinações ideais. Então, como, em uma psicologia intencional o objeto lógico possui existência em si reconhecida, apreendida e afirmada em juízos? Husserl alega três razões para tal: a) objetos ideais aparecem em diversos juízos de existência, e negar que eles existem seria contrariar o fazer matemático e $\operatorname{lógico}^{32}$; b) objetos ideais são visados por atos que se dirigem especificamente para tais atos, como a abstração ideatória e a intuição categorial $^{33}$; por fím, c) quando executamos atos expressivos e nós "vivemos" a linguagem, remetemo-nos a identidades de sentido, que nos garantem a cognoscibilidade e a comunicabilidade das expressões. Por exemplo, quando digo "cavalo", há um sentido idêntico na expressão desta classe animal, mesmo que eu não pense ou expresse esta classe ou alguém, em outros lugares e tempos, usem expressões diferentes. O sentido da classe "cavalo", mesmo expressado nos vocábulos "cavalo", caballo, horse, etc., permanece o mesmo.

Voltemo-nos, por outro lado, ao problema não menos importante de se definir o conceito de evidência como um possível critério objetivo de verdade. Evidência, em Husserl, designa tanto um ato psíquico quanto uma meta limite para o conhecimento - em contrapartida, há a meta negativa de

\footnotetext{
${ }^{31}$ Cf. HUSSERL, E. Investigaciones Lógicas - II Tomo. Traducción del alemán por Manuel García Morente y José Gaos. 2a Ed. Madrid: Revista de Occidente, 1967 (Selecta), p. 224-225, apêndice aos parágrafos 11 e 20 e HUSSERL, E. Investigaciones Lógicas - II Tomo. Traducción del alemán por Manuel García Morente y José Gaos. $2^{a}$ Ed. Madrid: Revista de Occidente, 1967 (Selecta), p. 177, §11.

${ }^{32} \mathrm{cf}$. HUSSERL, E. Investigaciones Lógicas - I Tomo. Traducción del alemán por Manuel García Morente y José Gaos. $2^{\text {a }}$ Ed. Madrid: Revista de Occidente, 1967 (Selecta), p. 422, §8.

${ }^{33}$ cf. HUSSERL, E. Investigaciones Lógicas - I Tomo. Traducción del alemán por Manuel García Morente y José Gaos. $2^{\text {a }}$ Ed. Madrid: Revista de Occidente, 1967 (Selecta), p. 411, §4.
}

\begin{tabular}{|c|c|c|c|c|c|}
\hline intuitio & $\begin{array}{c}\text { ISSN } \\
1983-4012\end{array}$ & Porto Alegre & Vol.9- $\mathrm{N}^{\circ} .1$ & $\begin{array}{l}\text { Julho } \\
2016\end{array}$ & p.35-52 \\
\hline
\end{tabular}


inevidência. É o ato sintetizador que, identificando e classificando um preenchimento de uma intenção como "adequado", afirma a adequação como acabada e confirmada por intuição. Seu correlato objetivo é a verdade, ou seja, a correspondência entre expressão e objeto. Não se trata de auto-evidência, ou seja, o sentimento de que uma determinada expressão é adequada a um determinado objeto, ou um ato psíquico real que dá um "distintivo" de verdade. Logo, não é porque uma determinada pessoa considera a expressão "casa verde" como adequada a uma casa de cor vermelha, mas quando esta pessoa efetua o ato expressivo e compreende que capta realmente uma casa verde. A evidência, portanto, é o ato em que se dá a verdade; Husserl nunca quis dizer que a evidência enquanto ato seria a própria verdade, o que retiraria a objetividade do próprio conhecimento. A última síntese de preenchimentos é o ato evidente, pois seu correlato é a própria adequação, o estado de coisas que é resultado de várias sínteses progressivas de adequação e "doação" do objeto à expressão, a própria verdade. O sentimento de evidência é um ato de presunção, e não um ato objetivante de caráter intuitivo: tal sentimento é uma antecipação, e não uma confirmação ou captação de objetos numa intuição.

Alguns comentadores dão modelos interpretativos que tentam identificar e resolver alguns destes problemas, analisando ou por meio de um modelo geral de concepções de linguagem ou uma recuperação de temas e argumentos presentes nas Investigações Lógicas. Vejamos quatro linhas teóricas principais: as interpretações de Martin Kusch, Dallas Willard, Emmanuel Lévinas e Henry Pietersma.

Dados estes problemas, podemos ver que, para Husserl, mesmo enfatizando o caráter neutro de sua epistemologia (não tende nem para o realismo ou idealismo, já que a natureza dos objetos não importa, mas os caracteres dos atos em que estes “aparecem”), tende a sempre crer que o que é objetivo, é apreensível. Não é diferente, para Martin Kusch, quando falamos da semântica: os significados são acessíveis, apreensíveis e não dependem de construções ou atos psíquicos. Há a possibilidade de entender os signos como reinterpretáveis, ou seja, podemos sair da linguagem para entendê-la e descobrir relações cada vez mais compreensivas de como atribuímos significados a objetos por meio da linguagem. Tal posição epistêmica e semântica é chamada por Kusch de concepção da linguagem como cálculo (grifo nosso).

Numa concepção de linguagem como cálculo, relações metalinguísticas como verdade e correspondência não só são comuns quanto necessárias, pois, sabendo que existe a meta da verdade como plena e consciente correspondência entre linguagem e objeto, depreende-se que podemos descrever a própria correspondência e estudá-la. Além disso, podemos estudar os próprios significados à parte das expressões e dos objetos a que se refere, o que pode ser demonstrado pelos estudos descritivos da $I$ Investigação e a gramática pura da IV Investigação. Husserl faz frente a concepções que consideram significado e linguagem como que entrelaçados de tal forma que um acesso à semântica e a noções metalinguísticas se torna impossível ou inviável, o que, segundo a terminologia de Martin Kusch,

\begin{tabular}{|c|c|l|l|l|l|}
\hline intuitio & $\begin{array}{c}\text { ISSN } \\
1983-4012\end{array}$ & Porto Alegre & Vol.9- $\mathrm{N}^{\mathrm{o}} .1$ & $\begin{array}{l}\text { Julho } \\
2016\end{array}$ & p.35-52 \\
\hline
\end{tabular}


caracteriza a concepção de linguagem como meio universal. O pai da fenomenologia, com efeito, através da psicologia intencional, do modelo psicológico e semântico intenção-preenchimento de significação, de seu realismo semântico, passando pela sua concepção de verdade e pela intuição categorial, tenta garantir e demonstrar que a linguagem alcança não só os significados, mas os objetos. Em primeiro lugar, a nossa vida psíquica está voltada ao objetivo; em segundo lugar, nossa linguagem carrega vivência que visam apreender significados e objetos; por fim, em terceiro lugar, decorrem destas concepções que é possível uma correspondência como "satisfação" ou "confirmação de intenção", e uma vivência que capta tal correspondência, inclusive para objetos que não são reais, já que existe uma série de intuições que acessam tais objetos.

Dallas Willard, por sua vez, vê as Investigações Lógicas como uma construção de uma semântica e uma epistemologia realistas, já que, partindo do conhecimento simbólico e mediato por meio de expressões, e através de atos intuitivos que se adequam (satisfazendo, como vimos, as intenções vazias de significado) ao conhecimento deste primeiro estágio, podemos sintetizar e ter evidência desta série de sínteses, e, por fim, chegar ao objetos como eles são ${ }^{34}$. A evidência seria a confirmação máxima de que a consciência alcançou o objeto efetivamente como ele se mostra e como ele é, e a verdade é o correlato desta confirmação.

Vemos, ainda, que o conceito de evidência adquire certa centralidade nas análises dos vários intérpretes de Husserl. Por isso, o interesse constante de Kusch ao analisar a evidência, pois, é mostrar que o conceito de evidência possibilita uma resposta aos antagonistas da linguagem como cálculo, isto é, abre caminho para que possamos sair da linguagem e descrever o conhecimento dos objetos e dos significados ${ }^{35}$. Willard, por sua vez, vê a evidência como o atestado de captação do objeto em si mesmo, na doação inteira e plena dos objetos, como ele é em si mesmo e como identidade com as intenções de significação ${ }^{36}$. Emmanuel Lévinas, de uma forma contundente, assevera claramente que em Husserl o fato de não se interpretar o ato de evidência como índice subjetivo de verdade nem uma validação por meios indutivos, como nas ciências empíricas se toma o conceito de evidência: "A evidência é definida

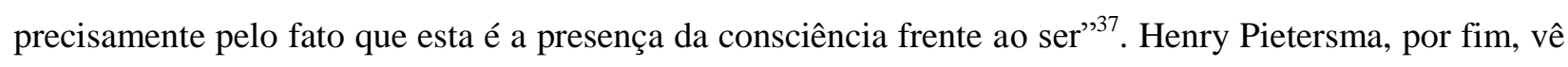

\footnotetext{
${ }^{34}$ WILLARD, D. Knowledge. In: Cambridge Companion to Husserl. Edited by Barry Smith and David Woodruff Smith. $1^{\text {a }}$ Ed. New York: Cambridge University Press, 1995, p.149 e 152; para entender a concepção realista da epistemologia husserliana, ver em continuidade WILLARD, Dallas. Knowledge. In: Cambridge Companion to Husserl. Edited by Barry Smith and David Woodruff Smith. New York: Cambridge University Press, 1995, p. 161162.

${ }^{35} \mathrm{cf}$. KUSCH, M. Linguagem como Cálculo versus Linguagem como meio universal: um estudo sobre Husserl, Heidegger e Gadamer. Tradução de Dankwart Bernsmüller. 1 ${ }^{a}$ Ed. São Leopoldo: Editora UNISINOS, 2001, p. 8687.

${ }^{36}$ WILLARD, D. Knowledge. In: Cambridge Companion to Husserl. Edited by Barry Smith and David Woodruff Smith. $1^{\text {a }}$ Ed. New York: Cambridge University Press, 1995, p.153-154.

${ }^{37}$ LÉVINAS, E. The Theory of Intuition in Husserl's Phenomenology. Translated by André Orianne. $2^{\mathrm{a}}$ Ed. Evanston: Northwestern University Press, 1995, p. 75.
}

\begin{tabular}{|c|c|l|l|l|l|}
\hline intuitio & $\begin{array}{c}\text { ISSN } \\
1983-4012\end{array}$ & Porto Alegre & Vol.9- $\mathrm{N}^{\mathrm{o}} .1$ & $\begin{array}{l}\text { Julho } \\
2016\end{array}$ & p.35-52 \\
\hline
\end{tabular}


a evidência como critério epistemológico, principalmente: distinguimos crenças justificadas das não justificadas racionalmente por meio de atos de evidência, ou seja, constatações de qua uma intenção vazia foi preenchida adequadamente ${ }^{38}$.

Em suma, podemos ver que entre os intérpretes que citamos acima, o conceito de evidência caracteriza-se como um conceito que transita dentro da epistemologia e da semântica, tanto como adequação de uma expressão ao seu sentido ideal quanto ao objeto ou estado de coisas referente, e também como distintivo entre expressões verdadeiras e falsas, pois dá às expressões adequadas o reconhecimento de correspondência; em termos husserlianos, entre expressões evidentes e não evidentes. Portanto, nossa hipótese é corroborada, nesta primeira instância, por vários referenciais teóricos: é possível que o conceito de evidência possa servir como meta de conhecimento e critério epistemológico e semântico. Passemos a uma análise e elucidação mais precisa destes caracteres do conceito de evidência, justificando-se, assim, a pertinência da já referida hipótese de interpretação.

\section{O conceito de evidência: a possibilidade de uma epistemologia apropriada à semântica husserliana}

Vemos, na seção anterior, que um dos temas mais problemáticos das Investigações Lógicas é o tema da evidência e o da verdade. $\mathrm{O}$ ato de evidência atua como comprovante da verdade, já que a tem como correlato objetivo. Neste sentido, distinguimos, sob os textos de Husserl, que evidência em sentido subjetivo e objetivo são intrinsecamente diferentes. Agora, vamos defender que o conceito e a teoria da evidência de Husserl possibilita uma epistemologia coerente com a semântica lógica husserliana, pelas razões que exporemos a seguir.

Além de estar tematizada na epistemologia husserliana, a evidência é o conceito que designa como aferimos a existência de objetos ideais. Por outro lado, é o ato objetivante por excelência. Enfim, a evidência é a meta limite do conhecimento, isto é, a consciência final dos preenchimentos de significação. Muito mais: em muitas análises fenomenológicas nas Investigações, Husserl se dirige sempre para o critério de evidência.

Cabe, agora, a pergunta: como a evidência atua tanto como critério de verdade? Torna-se possível interpretar este conceito deste modo? Como ato ou experiência da verdade, a evidência poderia manter seu caráter ao mesmo tempo epistemológico e semântico? A evidência, de certa forma, atua como critério distintivo entre enunciados verdadeiros e enunciados falsos, ou seja, enunciados que expressam preenchimento e enunciados que expressam decepções. Na I investigação, a função da análise simbólica

\footnotetext{
${ }^{38}$ PIETERSMA, H. Phenomenological Epistemology. $1^{\text {a }}$ Ed. New York: Oxford University Press, 2000, p. 40.
}

\begin{tabular}{|c|c|c|c|c|c|}
\hline intuitio & $\begin{array}{c}\text { ISSN } \\
1983-4012\end{array}$ & Porto Alegre & Vol.9- $\mathrm{N}^{\circ} .1$ & $\begin{array}{l}\text { Julho } \\
2016\end{array}$ & p.35-52 \\
\hline
\end{tabular}


Evidência e Significação nas Investigações Lógicas: o papel do conceito de evidência na semântica e na epistemologia de Husserl

sem intuição é substituída por uma análise que conta com os sentidos impletivos de um discurso, através do critério de evidência, ou seja, se a objetividade expressada é real e adequadamente dada ${ }^{39}$.

Husserl não é claro ao se determinar a evidência como critério formal ou material de verdade. Em uma passagem dos Prolegômenos, ele atesta que as leis e conceitos lógicos são reconhecidos como válidos e existentes por evidência - no caso, o termo usado é intelecção ${ }^{40}$. Contudo, ao longo da obra, nota-se que o critério de distinção de percepções adequadas e inadequadas ${ }^{41}$, é o de evidência, e, é claro, o ato que "dá" a verdade, e distingue expressões com conhecimento das meramente simbólicas por meio da evidência. Podemos ver que, em certos momentos, Husserl engendra numerosas descrições das sínteses em os objetos são conhecidos e dados como existentes. Há, portanto, uma circularidade entre captação de conteúdos intuitivos e posicionamento intencional, em que o primeiro vai se servindo de confirmação constante para o assentimento do ato posterior. É neste sentido que sempre se quer preservar a objetividade e a intersubjetividade do conhecido, pois a evidência é o ato que constata que a linguagem realmente alcançou os objetos e os objetos se corresponderam à linguagem. Em suma, não cria nem constrói objetos.

Vimos que a evidência é um ato de aplicação vasta dentro das Investigações. Contudo, este conceito, interpretado como critério de verdade, é realmente satisfatório para a semântica? O conceito de evidência consegue constatar que a objetividade não empírica é possível de ser adequada às expressões, isto é, é possível assegurar o preenchimento de intenções que se referem a objetos ideais e, portanto, atesta e compreende a apreensão de objetos semânticos? Sabemos que a evidência é um ato que é posicional, ou seja, "toma posição" sobre a existência de seu correlato objetivo. Então, como ele determina a existência de uma adequação deste tipo, sem apelar para uma existência apenas "dentro" de um ato? Segue-se disto a pergunta de como a instância epistemológica e a semântica encontram correspondência, a saber, tanto entre a objetividade ideal quanto aos objetos empíricos? Para responder a tais problemas, devemos distinguir certos pressupostos formais e não formais que permeiam o critério de evidência.

\footnotetext{
${ }^{39}$ Cf. HUSSERL, E. Investigaciones Lógicas - I Tomo. Traducción del alemán por Manuel García Morente y José Gaos. $2^{\text {a }}$ Ed. Madrid: Revista de Occidente, 1967 (Selecta), p. 365, §21.

${ }^{40}$ Morente e Gaos, com efeito, (em HUSSERL, E. Investigaciones Lógicas - I Tomo. Traducción del alemán por

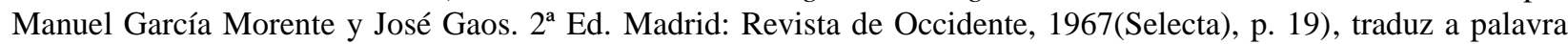
einsicht como intelección, isto é, um ato em que não só constatamos uma adequação entre expressão e intuição, mas a apreendemos em toda a sua plenitude. $\mathrm{O}$ exemplo que ele usa é o fato de que podemos ver que a proposição $1+2=2+1$ é verdadeira. A distinção entre evidência assertórica ("adequada") e evidência apodítica (intelecção), que Morente associa à diferença entre as palavras alemãs evidenz e einsicht, não estão no contexto das Investigações Lógicas, a não ser de modo implícito ou acrescentado nas edições posteriores a 1901 (ou seja, a de 1913 e 1921).

${ }^{41}$ Cf. MALDONADO, C. E.. Introducción a la Fenomenología a partir de la Idea de Mundo: la filosofía de Husserl. $1^{a}$ Ed: Santafé de Bogotá: (CEJA), 1995 (Colección Filosofía), p. 59-60 e HUSSERL, E. Investigações Lógicas - VI Investigação (Elementos de uma Elucidação Fenomenológica do Conhecimento. Tradução de Zeljko Loparic. $2^{\mathrm{a}}$ Ed. São Paulo; Abril Cultural, 1979, p.178, §3
}

\begin{tabular}{|c|c|l|l|l|l|}
\hline intuitio & $\begin{array}{c}\text { ISSN } \\
1983-4012\end{array}$ & Porto Alegre & Vol.9- $\mathrm{N}^{\mathrm{o}} .1$ & $\begin{array}{l}\text { Julho } \\
2016\end{array}$ & p.35-52 \\
\hline
\end{tabular}


Evidência e Significação nas Investigações Lógicas: o papel do conceito de evidência na semântica e na epistemologia de Husserl

Existem, dentro da dinâmica entre intenção e preenchimento de significação, leis ideais que impedem tanto que expressões absurdas quanto àquelas que pecam por "contrassenso"; logo, impedem $a$ priori qualquer adequação tanto por causa destas leis como por serem inevidentes. São leis gramaticais puras aquelas que impedem a combinação entre expressões anormais e são leis epistemológicas aquelas que descrevem e explicam como a inevidência, a incompatibilidade e a decepção se dão nesta dinâmica ${ }^{42}$.

Além destes caracteres, vemos que a evidência é critério que supõe algumas considerações psicológicas, semânticas e epistemológicas na relação entre objetidade empírica e objetividade lógica. Em primeiro lugar, psicologicamente falando, a matéria intencional de um ato de intenção de significação é uma instância de um objeto ideal a que esta intenção visa. Em segundo lugar, semanticamente falando, a um objeto ou estado de coisas ideais temos como correlatos ou instâncias diversos atos de significação, ou seja, à significação correspondem as expressões que são possíveis de serem preenchidas; mas, para que tais expressões que se referem a tais objetividades sejam satisfeitas, é preciso que um tipo especial de intuição as preencha, e esta é a função da percepção categorial, que apresenta a objetividade intencionada à expressão. Em terceiro lugar, a evidência é o ato que constata que tanto não se encontra uma objetividade lógica incompatível com a intenção de significação quanto que uma expressão anormal não pode comportar uma unidade semântica como correlato ${ }^{43}$.

Agora que a existência de objetos ideais é constatada por meio de evidência, isto se dá porque à intenção que justamente visa tais tipos de objetos, é constatado que preenchimentos confirmaram tais intenções. Não requer, como já elucidamos, nem um ato de mera indução de particulares nem mesmo uma ficção de objeto matemático; pelo contrário, quando intento um número primo, queremos apreender algo existente, e isto é feito pela percepção categorial. Pelos pressupostos anteriores, podemos ver que é verdadeiro, pois, se não há incompatibilidade gramatical nem epistêmica, e ter evidência deste enunciado é pressupor isto, ele pode ser constatado como verdadeiro. Como já enunciamos anteriormente, a percepção categorial não se faz sem uma base intuitiva sensível, ou seja, ela é fundada por atos perceptivos individuais sob os quais se faz uma síntese e se alcança um objeto de ordem superior.

Husserl, portanto, estaria entendendo a linguagem matemática literalmente? Certamente: atos categoriais não são atos de indução ou coleção de objetos, mas de síntese de conteúdos perceptivos e fundamento de captação para objetos ideais; nisso, ele viu que seria possível preencher as intenções dos enunciados existenciais e que a evidência de um enunciado estritamente formal teria conteúdo objetivo ideal, justamente porque nas intenções de significação se visa um conteúdo impletivo ideal, não importando, por conseguinte, o contexto em que esses atos são expressos. Portanto, se houver evidência de

\footnotetext{
${ }^{42}$ HUSSERL, Edmund. Investigaciones Lógicas - II Tomo. Traducción del alemán por Manuel García Morente y José Gaos. $2^{a}$ Ed. Madrid: Revista de Occidente, 1967 (Selecta), p. 127, §12.

${ }^{43}$ Ver HUSSERL, E. Investigaciones Lógicas - II Tomo. Traducción Del alemán por Manuel García Morente y José Gaos. 2a Ed. Madrid: Revista de Occidente, 1967 (Selecta), p. 449-450, §39.
}

\begin{tabular}{|c|c|c|c|c|c|}
\hline intuitio & $\begin{array}{c}\text { ISSN } \\
1983-4012\end{array}$ & Porto Alegre & Vol.9- $\mathrm{N}^{\circ} .1$ & $\begin{array}{l}\text { Julho } \\
2016\end{array}$ & p.35-52 \\
\hline
\end{tabular}


Evidência e Significação nas Investigações Lógicas: o papel do conceito de evidência na semântica e na epistemologia de Husserl

preenchimentos destas intenções, posso constatar que são existentes (não de modo empírico, mas como válidos idealmente) e estão conformes aos enunciados que se referem a eles. Evidenciar a verdade de um juízo é ver que a plenitude intuitiva é a mais real, extensa e vivaz possível, que houve a satisfação de todos os conteúdos simbólicos pelos objetos a que se referem, e, além do mais, é verificar que expressão e intuição são conformes, seja quais objetos forem os correlatos destes atos.

\section{Considerações Finais}

O critério da evidência - e essa é a maior dificuldade conceitual e teórica - é um critério diferenciado de verdade, pois não é algorítmico, mas epistemológico, semântico e psicológico. Não é, novamente enfatizando, um ato psíquico de revisão introspectiva - uma espécie de "sentimento" de evidência - mas de constatação e apreensão de uma objetividade: a objetividade da verdade. Além disso, é um critério que supõe regras semânticas de formação e relação entre expressões. Sua objetividade se baseia tanto no fato de que não só a) pressupõe regras semânticas de compatibilidade e incompatibilidade entre expressões e objetos como b) capta como "situação objetiva" uma série total e completa de adequações, e, neste sentido, a evidência não é um sentimento, mas um atestado, e, sendo assim, c) atua como critério semântico, ou seja, distingue expressões satisfeitas e não satisfeitas por intuição e, por outro lado, concebida como meta de conhecimento, distingue as captações adequadas das inadequadas.

Com relação aos problemas supracitados, ou seja, referente aos objetos ideais, a evidência é possível como critério ou atestado de verdade em proposições formais justamente porque:

a) Expressões de caráter categorial bem-formadas são somente passíveis de preenchimento por percepções categoriais, dando-as objetos ideais e, por isso,

b) Os atos em que se dão objetos ideais e não ficções são os atos de percepção categorial; sendo assim,

c) Husserl entende que objetos ideais podem entrar nas dinâmicas de adequação, e, por fim, serem objeto de evidência, e, por fim,

d) Podemos, em atos de evidência, constatar a "existência ideal" destes objetos, e somente por meio destes atos. A validade ideal, portanto, é condição para a apreensão adequada.

Pode-se questionar, ainda, se realmente não poderíamos prescindir de objetos lógicos pela eficiência científica ao invés de adentrarmos a estes problemas de natureza ontológica. A este problema, Husserl responde dizendo que a lógica pura, enquanto teoria ideal de todas as ciências, não comunga com um interesse prático, mas um interesse teórico, igualmente legítimo, de explicação científica ${ }^{44}$. Ademais,

${ }^{44}$ Ver HUSSERL, E.. Investigaciones Lógicas - I Tomo. Traducción del alemán Manuel García Morente y José Gaos. $2^{\circ}$ Ed. Madrid: Revista de Occidente, 1967 (Selecta), p. 264-265, §64. Tal referência se faz necessária, porque o

\begin{tabular}{|c|c|c|c|c|c|}
\hline intuitio & $\begin{array}{c}\text { ISSN } \\
1983-4012\end{array}$ & Porto Alegre & Vol.9- $\mathrm{N}^{\circ} .1$ & $\begin{array}{l}\text { Julho } \\
2016\end{array}$ & p.35-52 \\
\hline
\end{tabular}


Evidência e Significação nas Investigações Lógicas: o papel do conceito de evidência na semântica e na epistemologia de Husserl

insistimos que Husserl clarifica o caso de que temos evidência de proposições formais, e, além disso, constatamos e reconhecemos a proposição respectiva como verdadeira; não há comprometimento com questões fora da lógica e teoria do conhecimento na psicologia descritiva husserliana, pois o que entra em jogo na teoria do conhecimento não é o aspecto metafísico, mas epistemológico, ou seja, o objeto ideal é descrito enquanto objeto para atos de conhecimentos específicos.

\section{Referências}

HUSSERL, E. Investigações Lógicas - VI Investigação Lógica (Elementos de uma Elucidação Fenomenológica do Conhecimento). Tradução de Zeljko Loparic e Andreia Maria Altino de Campos Loparic. $2^{\circ}$ Ed. São Paulo: Abril Cultural, 1979 . Investigaciones Lógicas- I Tomo. Traducción del alemán por Manuel G. Morente y José Gaos. $2^{\mathrm{a}}$ Ed. Madrid: Revista de Occidente, 1967(Selecta). . Investigaciones Lógicas - II Tomo. Traducción del alemán Manuel G. Morente. $2^{\mathrm{a}}$ Ed. Madrid:

Revista de Occidente, 1967(Selecta).

KUSCH, M. Linguagem como cálculo e linguagem como meio universal - Um estudo sobre Husserl, Heidegger e Gadamer. Tradução de Dankwart Bernsmüller. São Leopoldo: $1^{\circ}$ Edição, 2001.

LÉVINAS, E. The Theory of Intuition in Husserl's Phenomenology. Translated by André Orianne. $2^{\mathrm{a}}$ Ed. Evanston: Northwestern University Press, 1995.

MALDONADO, C. E. Introducción a la Fenomenología a partir de la Idea del Mundo: La Filosofía de Husserl. $1^{\mathrm{a}}$ Ed. Santafé de Bogotá: Centro Editorial Javeriano (CEJA), 1995 (Colección Filosofía).

PETERSMA, H. Phenomenological Epistemology. $1^{\mathrm{a}}$ Ed. New York: Oxford University Press, 2000.

WILLARD, D. Knowledge. In: Cambridge Companion to Husserl. Edited by Barry Smith and David Woodruff Smith. $1^{a}$ Ed. New York: Cambridge University Press, 1995, p. 138-167.

Recebido em: 30/04/2015

Aprovado para a publicação em: 08/06/2016

interesse teórico puro e não pragmático (embora sem menosprezar outros interesses) dirige tanto a construção de uma lógica pura e o esclarecimento epistemológico da mesma, ou seja, as descrições fenomenológicas.

\begin{tabular}{|c|c|l|l|l|l|}
\hline intuitio & $\begin{array}{c}\text { ISSN } \\
1983-4012\end{array}$ & Porto Alegre & Vol.9- $\mathrm{N}^{\mathrm{o}} .1$ & $\begin{array}{l}\text { Julho } \\
2016\end{array}$ & p.35-52 \\
\hline
\end{tabular}

